DE

DE GRUYTER

OPEN
Journal of Intercultural Management

Vol. 7, No. 3, September 2015, pp. 15-37

DOI 10.1515/joim-2015-0019

Mehmood Anjum ${ }^{4}$

Federal Urdu University, Gulshan-e-Iqbal Campus, Karachi, Pakistan

Syed Muhammad Zia ${ }^{5}$

Federal Urdu University, Gulshan-e-lqbal Campus, Karachi, Pakistan

Waheed Ahmed Khan ${ }^{6}$

Federal Urdu University, Gulshan-e-Iqbal Campus, Karachi, Pakistan

\title{
Cultural Comparison of Trait Emotional Intelligence among the Provinces of Pakistan (Sindh, Punjab, Khyber Pakhtunkhwa and Balochistan)
}

\begin{abstract}
The important feature of effective manager is to understand emotions in an effective method. This study looks into cultural variations in trait Emotional Intelligence among the business managers from the provinces of Pakistan i.e. Sindh, Punjab, Khyber Pakhtunkhwa and Balochistan. Comparing rotated component matrixes of these four provinces revealed the four traits emotional intelligence factors, Well-being, Selfcontrol, Emotionality, and Sociability of these provinces. Short-form of Trait emotional intelligence Questionnaire developed by Petrides [2009] has employed to measure the 404 business managers from four provinces in present article. The results revealed evident the cultural differences in trait emotional intelligence scores with the business managers of Sindh scoring consistently higher than other three provinces and the business managers from Balochistan province scores are at lowest. These cross cultural

\footnotetext{
${ }^{4}$ mehmood.university@gmail.com

5syedmzia@gmail.com

${ }^{6}$ waheedresults@gmail.com
} 
differences may have ramification for global El trait, well-being, self-control, emotionality and sociability in business manager's performance, negotiation, conflict management, decision making and organizational development.

\section{Introduction}

Emotional intelligence is acknowledged as core to leadership strategy incorporate as an aspect of the essential skills, capabilities and personal behaviors of managers to deal with and manage correctly with employees and to bring change for the advancement of organization, Singh, Manser, and Mestry [2007]. The model of Trait emotional intelligence centers on traits associated to social behavior produces social intelligence and personality traits connected to emotions produces emotional intelligence.

A most significant factor, emotional intelligence found in high performing business managers and Bostjancic [2010] discovered that managers who properly managed their emotions and signals were more pleased with their work and also perform better. Trait emotional intelligence is explained by Petrides, Pita, \& Kokkinaki [2007] as a constellation of emotional self-perceptions situated at the lower degrees of personality hierarchies. The framework of trait emotional intelligence delivers extensive coverage of personality facets related to affects and trait emotional intelligence creates each individual's personality unique. Grewal \& Salovey [2005] accepted that individuals from dissimilar cultural backgrounds differently interpret and use emotional information and facts.

The provinces of Pakistan i.e. Sindh, Punjab, Khyber Pakhtunkhwa and Balochistan have unique and dissimilar cultures, languages, and traditions already proved by Mehmood \& Zia et al. [2015]. The workforce from these four provinces is working in public and private sector national and global organizations. Ang. et al. [2007] accepted that an individual, who is emotionally intelligent in one particular culture, might not be that in another one. It is a need of organizations to find business managers who are emotionally intelligent in various cultural settings. The emotional intelligence is very important during the selection and recruitment and performance management process of expatriate managers. Therefore, national and global organizations must have better understanding of trait emotional intelligence in order to staffing, customizing businesses effectively as a unified entity in accordance to cultural needs of the local and global market.

This research aims to examine the cultural differences in trait emotional intelligence by exploring differences among the business managers of the provinces of Pakistan. The results of the research will assist and provide guideline not only to business managers but also to national and international organizations who are operating in these four provinces to be competent in trait of emotional intelligence in different cultural settings. 


\section{Theoretical Background}

The emotional intelligence term came into sight a number of times in the literature explained by Greenspan [1989]. There are two prominent approaches located in the literature that contemplate Emotional Intelligence dimensions:

The first approach is Ability Emotional Intelligence, relates to cognitive abilities and is tested by performance measurements. Salovey and Mayer [1990; 1997] defined emotional intelligence as an "ability to perceive, appraise, and express emotion; using emotion to facilitate thought; to understand emotion; and an ability to control emotions to promote emotional and intellectual growth". Ortony, Revelle, and Zinbarg [2007]; Keele and Bell [2008]; Rossen, Kranzler, and Algina [2008] mentioned the weaknesses in the concept of emotional intelligence as an ability and also the challenges that occur from neglecting the inherently subjective dynamics of emotions.

In accordance to Perez, Petrides and Furnham [2005], different standard cognitive ability assessments, assessments of ability emotional intelligence are not able to score objectively for the reason there are no definite key elements for what constitutes an accurate result. Ability emotional intelligence assessments have used to sidestep this issue by relying on substitute scoring methods, which have also been applied earlier for dealing with similar complications in the operationalization of social intelligence. Petrides, Frederickson, Furnham [2004], explained that many intrapersonal ingredient of ability emotional intelligence is not responsive to objective scoring, simply because the information and facts needed for such scoring is accessible only to the assessor. Psychological indices of emotions have to be confirmed with reference point to men and women unique reports of their feelings.

The subsequent approach of Trait Emotional Intelligence developed by Petrides, Furnham [2003] and they point out that traits emotional intelligence is composed of self perceptions and behavioral dispositions, which are suitable with the subjective dynamics of emotions. It is tested with self-report measurements described by Bar-On [2000] and Mayer, Caruso \& Salovey [2000]. Its mean trait emotional intelligence was involved with cross situational consistencies in behavior, and implanted within the personality framework, and is examined by using validated self-report inventories that measure regular behavior.

Trait emotional intelligence approach has a number of advantages comparatively to others, it understands the subjective nature of emotional experience revealed by Robinson \& Clore (2002), as a result avoid a number of difficulties afflicting other models. Trait emotional intelligence also combines the construct into popular theories of differential psychology instead of treating it as a novel entity separated from gathered scientific knowledge. It is not linked to particular exclusive assessments, but rather it is standard and presents a foundation for the presentation of information from any survey of emotional intelligence or relevant constructs. 
Vernon, Villani, Schermer \& Petrides [2008] investigated that the trait emotional intelligence facets are as personality traits. The connection between traits of personality and trait emotional intelligence discovered by Besharat [2010]; SanchezRuiz et al [2010]; Petrides et al [2010] and Khalatbari et al [2011]. Personality as a source of emotions has been firmly proved by Stephen P. Robbins \& Timothy A. Judge [2014] and personality is formed by both genetic and environmental affects but the most significant of the latter are cultural influences and the elements which link culture to personality are cultural values and norms was identified by Harry C. Triandis and Eunkook M. Suh [2002]. Some individuals display anger as an emotion on criticism but some seem calm and relax and take criticism as an opportunity for improvement. These dissimilar reactions explain the different trait components of their personalities and people's emotions vary across cultures stated by Stephen P. Robbins \& Timothy A. Judge [2014].

Behavioral scientists consent on the premise that personality traits and emotions are culturally and socially formed and maintained stated by Berry, Poortinga, Segall, \& Dasen [2002]. The norms of cultures also influence behavioral responses to emotions. Van Maanen and Kunda [1989] claim that norms manage emotional displays by understanding the emotions regarded acceptable to expose in particular contexts. Gross, J.J. \& John [1998] further investigated and mentioned about social norms that rule how individuals should really feel at particular times. Miyamoto \& Ryff [2011] employed the phrase cultural scripts to recommend to cultural norms that influence how individuals expect emotions to be managed. It means cultural impacts on the emotion process are mediated to a significant extent by the importance an emotion has for a person.

Various ethnographic scientific studies recommend cultural dissimilarities in social consequences, especially when it comes to examining emotions. Scholars have extensive mentioned the need for non-natives to a community to observe behavior to figure out norms about socially appropriate replies to emotion expressed by Weick [1995]. The cultural norms influence emotion and affect a group's ability to manage emotion by their affect on emotional capacity of group or a degree of tolerance for approaching, participating to, or conversing emotion, Holmer [1994] extensively acknowledged that cultures have unique display rules or norms that impact on the management of emotion and generate common function and predictability among people in their reaction to emotional stimuli. Druskat and Wolff [2001a; 2001b] stated that communities differ in their capability to develop cultural norms that have a favorable influence on the emotional process (i.e., how members interpret and respond to emotion), and on developing the group's emotional potential.

Many global organizations are operating and several approaching to utilize business opportunities in the four provinces of Pakistan. Adler [2002] stated that the business achievements, profitability and success of organization are depended intensely on effective and efficient managers. Ahmetoglu at el. [2011] expressed 
that emotionally intelligent managers are more likely to engage in innovative entrepreneurial activities and the competency in emotional intelligence is an essential predictor for the success of manager and organization. The effect of emotional intelligence on work outcomes was tested empirically by Gross [1998] in his emotion control model. The attraction of emotional intelligence has been consistently supported by claims expressing that it is a foundation of successful manager and employee's job performance justified by Joseph \& Newman [2010].

Culture decides the values and norms of people and the cultural norms also figure out the significance of emotions and also managing of them. The favorable influence of culture on employee's job performance of workforce and organizational productivity has been verified specifically in the context of the culture of Pakistan by Mehmood at el. [2013]. It was expressed by Druskat V., and Wolff [2001b] that emotional skilled group norms is relevant to group emotion where it controls the behavior of group associates towards other associates, the group level of group emotion where it controls behavior of team members toward the team as a whole, or the cross-boundary (external) level of group emotion where it controls behavior of team members towards those outside of the team; these degrees are reliable with those suggested by Arrow, McGrath, and Berdahl [2000].

As a multicultural state the provinces of Pakistan have great diversity of cultural activities, languages, consuetudes, traditions and religious rituals revealed by Mehmood at. el. [2015]. Culture have considerable influence on emotional expression and the indigenous emotional responses shown by associates of various countries and ethnic communities stated by Caruso \& Salovey [2004]. The norms of culture influence the definition of occasions and the behavioral reaction to those occasions. As Stubbs and Messer [2003] have revealed, communities differ in their capability to work with emotion and create group capability to deal with emotional concerns. Druskat and Wolff [2001a] have recognized the existence of group-level capabilities, which indicate the capability of group to produce group norms that influence and regulate the emotional process in a way that develops emotional potential and builds up cultural capital and leads to efficiency.

The research on cultural variations in trait emotional intelligent particularly in the context of four provinces of Pakistan has not been found in the literature. Cultural differences clearly exist among the provinces of Pakistan and previous research has discovered already the differences among these four cultures proved by Mehmood \& Zia at el. [2015].

After reviewing above literature, following questions were hypothesized:

H0: The trait emotional intelligence scores of business managers from four provinces of Pakistan are significantly similar to each other.

H1: The trait emotional intelligence scores of business managers from four provinces of Pakistan are significantly different to each other. 
This research may provide more comprehensive understanding cultural variations in trait emotional intelligence and comparison of trait emotional intelligence scores of business managers of these four provinces of Pakistan may help national and international organizations in the areas of recruitment, performance and conflict management, workgroup cohesion, organizational commitment, development and citizenship.

\section{Participants}

This research composed total 404 business managers from four provinces. 73 male and 39 females from province of Sindh (including 26 senior managers, 39 managers and 47 assistant managers), from province of Punjab were 95 males and 46 females (including 24 senior managers, 48 managers and 69 assistant managers), from province of Khyber Pakhtunkhwa were 69 males and 19 females (including 9 senior managers, 22 managers and 57 assistant managers) and from the province of Balochistan were 52 males and 11 females (including 6 senior managers, 11 managers and 46 assistant managers). The participants randomly selected from the 19 private sector organizations of Pakistan and all of them completed the English version of TEIQue-SF. The participant's education was graduation to master degree and working experience was 4 to 26 years. The age range of participants was 21 to 55 years. Participants were asked to complete the questionnaire and they were categorized either as Senior Managers, Managers and Assistant Managers from the provinces of Sindh, Punjab, Khyber Pakhtunkhwa and Balochistan. Total 460 questionnaires were distributed 437 were returned and 33 were uncompleted and only 404 were utilized in this research. The response rate was $92.44 \%$.

\section{Data Elicitation Instrument}

To measure the Trait emotional intelligence of participants, the short-form of Trait Emotional Intelligence Questionnaire developed by Petrides [2009] was employed which offers extensive coverage of the trait emotional intelligence sampling domain. A range of TEIQue's forms are adapted and validated in numerous researches which concentrated primarily on trait emotional intelligence verified by Furnham \& Petrides [2003]; Petrides Frederickson, \& Furnham [2004]. The questionnaire was comprised on 30-item inventory. This measure produces scores on 15 emotion-related facets, four factors, Well-being, Self-control, Emotionality, and Sociability. Participants are needed to reply on a 7-point Likert scale ranging from " $1=$ completely disagree" to " $7=$ completely agree". The questionnaire requires less than 10 minutes to finish, therefore ensuring that participants do not suffer question fatigue, stated by Bryman and Bell [2003; 2007] and thus take less care about their responses. Well-being is comprised of questions 5, 9, 12, 20, 24 and 27. Self-control is comprised of questions 4, 7, 15, 19, 22 and 30. Emotionality is 
comprised of questions $1,2,8,13,16,17,23$ and 28. Sociability is comprised of 6 , $10,11,21,25$, and 26. The trait emotional intelligence scores comprised on (selfmotivation $=$ questions 3, 18 and adoptability $=$ questions 14 and 29). Questions 2, 4, $5,7,8,10,12,13,14,16,18,22,25,26$, and 28 are reverse-coded. The Cronbach alpha value for TEIQue factors (well-being, self-control, emotionality and sociability) of Sindh, Punjab, Khyber Pakhtunkhwa and Balochistan provinces was (0.81) for this research and it is acceptable and reliable.

\section{Factor Analysis}

Petrides and Furnham [2000] recommended factor analysis prior to applying trait emotional intelligence scale, thus, confirmatory factor analysis of four provinces data was performed by utilizing principal components analysis with varimax rotation technique and all calculations are produced on SPSS version 11.2. Ultimate solution of principal component analysis was centered on the extraction of 4 factors, being communality value for each variable greater than 0.50 . This technique has employed to figure out the factor structure of trait emotional intelligence in each of the four provinces samples and the scree plot methods were instructed for the selection of four factors.

Table 1. Rotated Component Matrix Pattern of Sindh Province

\begin{tabular}{|l|l|l|l|l|}
\hline & Self-control & Emotionality & Sociability & Well-Being \\
\hline Emotion Regulation & $\mathbf{0 . 8 1 1}$ & 0.045 & 0.086 & -0.042 \\
\hline Stress Management & $\mathbf{0 . 6 9 6}$ & 0.001 & -0.223 & 0.14 \\
\hline Impulse-control & $\mathbf{0 . 6 6 1}$ & -0.046 & 0.217 & -0.061 \\
\hline Relationships & -0.168 & $\mathbf{0 . 7 5 3}$ & -0.092 & -0.103 \\
\hline Empathy & -0.073 & $\mathbf{- 0 . 7 4 6}$ & 0.224 & -0.084 \\
\hline Emotion Expression & 0.257 & $\mathbf{0 . 6 9 4}$ & 0.283 & -0.056 \\
\hline Emotion Perception & 0.456 & $\mathbf{- 0 . 5 3}$ & 0.072 & -0.046 \\
\hline Emotion Management & 0.174 & 0.041 & $\mathbf{0 . 7 7 7}$ & 0.101 \\
\hline Assertiveness & 0.296 & -0.322 & $\mathbf{0 . 7 1 2}$ & -0.231 \\
\hline Social Awareness & -0.204 & -0.036 & $\mathbf{0 . 6 8 5}$ & 0.081 \\
\hline Self-esteem & -0.027 & 0.071 & 0.022 & $\mathbf{0 . 7 8 9}$ \\
\hline Happiness & 0.008 & 0.115 & 0.191 & $\mathbf{- 0 . 7 3 7}$ \\
\hline Optimism & 0.04 & 0.002 & 0.239 & $\mathbf{0 . 6 9 7}$ \\
\hline
\end{tabular}

Source: own work.

Rotated Component Matrix for the Province of Sindh mentioned in Table 1, total four factors are extracted and the variances of four unrotated factors were $19.89 \%, 14.10 \%, 13.50 \%$ and $12.13 \%$ respectively, total variance was $56.629 \%$. The scree plot for the province of Sindh indicated that there were four possible common factors emerging from the data set as presented in table-1.The facets of emotion regulation, stress management and impulse-control are added in first factor self- 
control. Relationships, empathy, emotion expression and emotion perception and added in factor two emotionality. Emotion management, assertiveness and social awareness are added in sociability. Self-esteem, happiness and optimism are added in fourth factor well-being.

Table 2. Rotated Component Matrix Pattern of Punjab Province

\begin{tabular}{|l|l|l|l|l|}
\hline & Emotionality & Sociability & Well-Being & Self-control \\
\hline Relationships & $\mathbf{0 . 7 6 2}$ & -0.308 & -0.2 & 0.026 \\
\hline Emotion Perception & $\mathbf{0 . 6 6 3}$ & 0.006 & 0.289 & -0.175 \\
\hline Empathy & $\mathbf{- 0 . 6 7 4}$ & -0.279 & -0.043 & -0.269 \\
\hline Emotion Expression & $\mathbf{- 0 . 5 5 3}$ & -0.247 & 0.021 & 0.258 \\
\hline Impulse-control & -0.018 & $\mathbf{0 . 6 4 6}$ & -0.194 & 0.311 \\
\hline Stress Management & 0.087 & $\mathbf{- 0 . 6 5 9}$ & 0.092 & 0.12 \\
\hline Emotion Regulation & 0.14 & $\mathbf{0 . 6 1 1}$ & 0.12 & -0.001 \\
\hline Happiness & 0.031 & -0.066 & $\mathbf{0 . 6 8 7}$ & -0.023 \\
\hline Optimism & 0.065 & 0.084 & $\mathbf{0 . 6 5}$ & 0.018 \\
\hline Self-esteem & 0.049 & 0.093 & $\mathbf{- . 7 5 6 -}$ & -0.86 \\
\hline Assertiveness & -0.023 & 0.131 & 0.14 & $\mathbf{0 . 6 5 2}$ \\
\hline Emotion Management & 0.117 & -0.078 & 0.068 & $\mathbf{- 0 . 7 6 7}$ \\
\hline Social Awareness & 0.055 & -0.161 & 0.063 & $\mathbf{0 . 6 7 5}$ \\
\hline
\end{tabular}

Source: own work.

In the table 2, Rotated Component Matrix for the Province of Punjab, total four factors are extracted and the variances of four unrotated factors were $15.32 \%$, $14.30 \%, 12.50 \%$ and $9.87 \%$ respectively, total variance was $51.99 \%$. The scree plot for the province of Punjab indicated that there were four possible common factors emerging from the data set as presented in table 2. The facets of relationships, emotion perception, empathy and emotion expression and added in first factor emotionality. The facets of impulse-control, stress management and emotion regulation are added in second factor sociability. The facets of happiness, optimism, self-esteem are added in third factor well-being. The facets of assertiveness, emotion management and social awareness are added in fourth factor self-control. 
Table 3. Rotated Component Matrix Pattern of Khyber Pakhtunkhwa Province

\begin{tabular}{|l|l|l|l|l|}
\hline & Well-Being & Self-control & Emotionality & Sociability \\
\hline Self-esteem & $\mathbf{0 . 7 4 9}$ & 0.021 & 0.325 & 0.084 \\
\hline Happiness & $\mathbf{0 . 6 6 6}$ & 0.205 & 0.042 & 0.091 \\
\hline Optimism & $\mathbf{0 . 6 4 3}$ & 0.14 & -0.093 & 0.006 \\
\hline Stress Management & -0.087 & $\mathbf{- 0 . 6 7 8}$ & -0.257 & -0.025 \\
\hline Impulse-control & -0.235 & $\mathbf{- 0 . 6 6 9}$ & 0.104 & -0.324 \\
\hline Emotion Regulation & 0.271 & $\mathbf{0 . 6 2 3}$ & -0.037 & -0.436 \\
\hline Emotion Perception & 0.131 & 0.227 & $\mathbf{0 . 5 8 9}$ & -0.405 \\
\hline Relationships & 0.1 & -0.007 & $\mathbf{0 . 5 3 7}$ & 0.063 \\
\hline Emotion Expression & -0.346 & 0.282 & $\mathbf{0 . 5 3 2}$ & 0.129 \\
\hline Empathy & 0.082 & -0.238 & $\mathbf{0 . 5 0 5}$ & 0.462 \\
\hline Emotion Management & 0.079 & 0.137 & 0.249 & $\mathbf{0 . 7 1}$ \\
\hline Assertiveness & -0.029 & 0.244 & -0.246 & $\mathbf{0 . 6 9}$ \\
\hline Social Awareness & 0.113 & -0.096 & 0.063 & $\mathbf{0 . 6 3 3}$ \\
\hline
\end{tabular}

Source: own work.

In the table 3, Rotated Component Matrix for the Province of Khyber Pakhtunkhwa, total four factors are extracted and the variances of four unrotated factors were $18.60 \%, 15.58 \%, 10.50 \%$ and $8.75 \%$ respectively, total variance was $53.44 \%$. The scree plot for the province of Khyber Pakhtunkhwa indicated that there were four possible common factors emerging from the data set as presented in table-3. The facets of self-esteem, happiness and optimism, are added in factor first factor well-being. The facets of stress management, impulse-control, and emotion regulation are added in second factor self-control. Emotion perception, relationships, emotion expression and empathy added in third factor emotionality. Emotion management, assertiveness, and social awareness are added in fourth factor sociability.

Table 4. Rotated Component Matrix Pattern of Balochistan Province

\begin{tabular}{|l|l|l|l|l|}
\hline & Self-control & Emotionality & Sociability & Well-Being \\
\hline Impulse-control & $\mathbf{0 . 8 1}$ & 0.123 & 0.195 & 0.108 \\
\hline Emotion Regulation & $\mathbf{0 . 7 3 4}$ & 0.245 & -0.047 & 0.298 \\
\hline Stress Management & $\mathbf{- 0 . 6 1 2}$ & -0.346 & -0.312 & -0.296 \\
\hline Relationships & 0.296 & $\mathbf{0 . 7 8}$ & 0.1 & 0.177 \\
\hline Emotion Perception & 0.451 & $\mathbf{0 . 7 0 8}$ & -0.157 & -0.143 \\
\hline Empathy & -0.118 & $\mathbf{0 . 6 2 1}$ & 0.063 & 0.489 \\
\hline Emotion Expression & 0.346 & $\mathbf{0 . 5 7 8}$ & 0.181 & 0.453 \\
\hline Emotion Management & 0.322 & -0.161 & $\mathbf{0 . 7 3 8}$ & 0.132 \\
\hline Assertiveness & -0.24 & 0.344 & $\mathbf{0 . 6 7 8}$ & -0.323 \\
\hline Social Awareness & 0.171 & 0.071 & $\mathbf{0 . 5 4 3}$ & 0.429 \\
\hline Self-esteem & 0.048 & 0.281 & -0.033 & $\mathbf{0 . 6 8 8}$ \\
\hline
\end{tabular}




\begin{tabular}{|l|l|l|l|l|}
\hline Happiness & -0.178 & 0.017 & -0.182 & $\mathbf{- 0 . 6 5 5}$ \\
\hline Optimism & -0.248 & -0.08 & 0.021 & $\mathbf{- 0 . 6 3 2}$ \\
\hline
\end{tabular}

Source: own work.

In the table 4, Rotated Component Matrix for the Province of Balochistan, total four factors are extracted and the variances of four unrotated factors were $34.82 \%, 10.80 \%, 10.13 \%$ and $8.64 \%$ respectively, total variance was $64.40 \%$. The scree plot for the province of Balochistan indicated that there were four possible common factors emerging from the data set as presented in table-4. The facets of impulse-control, emotion regulation and stress management are added in first factor self-control. The facets of relationships, emotion perception, empathy and emotion expression added in second factor emotionality. Emotion management, assertiveness and social awareness added in third factor sociability. The facets of elf-esteem, happiness and optimism added in fourth factor well-being.

\section{Comparison of Factor Analysis}

The cross cultural verification trait emotional intelligence has been proven in the factor analysis of TEIQue facets, which are presented in rotated component matrixes of Sindh, Punjab, Khyber Pakhtunkhwa and Balochistan provinces. The Sindh and Balochistan provinces matrixes showed similarity with each other. The factor of Self-Control is the showed as a first factor in both matrixes but the impulse control facet is top in Balochistan province and the facet of emotion regulation is top on Sindh province rotated component matrix. The Punjab and Khyber Pakhtunkhwa rotated component matrixes are significantly dissimilar, not only from each other but also from Sindh and Balochistan provinces.

The province of Khyber Pakhtunkhwa matrix showed the factor of Well-being as a first factor and facet of emotionality as first factor in Punjab rotated component matrix. The facet of self-esteem in Well-being factor showed top and emotion perception is showed top in Emotionality factor in Khyber Pakhtunkhwa matrix. The facet of happiness in Well-being factor is top and relationship in Emotionality factor is showed top in Punjab province matrix.

\section{Analysis of Data}

One Way ANOVA was performed to compare the scores of four provinces. The results of global EI traits, $\mathrm{F}=61.492$, $\mathrm{df}=3,400$ and $\mathrm{P}<0.001$, well-being, $\mathrm{F}=75.842$, $\mathrm{df}=3,400$ and $\mathrm{P}<0.001$, self-control, $\mathrm{F}=114.378, \mathrm{df}=3,400, \mathrm{P}<0.001$, emotionality, $\mathrm{F}=144.164, \mathrm{df}=3,400$ and $\mathrm{P}<0.001$ and sociability, $\mathrm{F}=103.618, \mathrm{df}=3,400$ and $\mathrm{p}<0.001$ provide statistically significant confirmation that means of global EI trait, wellbeing, self-control, emotionality and sociability are not same for four provinces. The $\mathrm{P}$-values show $\mathrm{P}<0.001$, which reject the null hypothesis. The outcomes are 
shown in table 5, firmly demonstrated the significant variations in trait emotional intelligence among the four province of Pakistan.

Table 5. Mean Scores of four Provinces

\begin{tabular}{|l|l|l|l|l|l|l|l|l|}
\hline & \multicolumn{3}{|l|}{ Sindh } & \multicolumn{3}{l|}{ Punjab } \\
& & \multicolumn{3}{l}{$\begin{array}{l}\text { Khyber } \\
\text { Pakhtunkhwa }\end{array}$} & \multicolumn{2}{l|}{ Balochistan } \\
\hline & Mean & SD & Mean & SD & Mean & SD & Mean & SD \\
\hline Global trait & 6.098 & 1.638 & 5.170 & 1.483 & 4.136 & 0.972 & 3.476 & 1.060 \\
\hline Well-being & 17.258 & 2.196 & 16.219 & 2.018 & 13.840 & 1.850 & 13.619 & 1.539 \\
\hline Self-Control & 18.508 & 2.831 & 16.418 & 2.025 & 14.272 & 1.069 & 13.127 & 0.791 \\
\hline Emotionality & 24.133 & 2.055 & 22.723 & 2.151 & 18.636 & 2.600 & 17.952 & 3.133 \\
\hline Sociability & 17.776 & 3.424 & 17.645 & 1.744 & 13.897 & 1.924 & 12.650 & 2.208 \\
\hline
\end{tabular}

Source: own work.

Post hoc analysis has performed to compare the trait emotional intelligence of four provinces and results indicated that the province of Sindh scores of global EI trait $(M=6.098$, Std. Dev.=1.638), well-being $(M=17.258$, Std. Dev.=2.196), selfcontrol $(\mathrm{M}=18.508$, Std. Dev.=2.831), emotionality $(\mathrm{M}=24.133$, Std. Dev.=2.055) and sociability $(M=17.776$, Std. Dev.=3.424) of Sindh province are significantly highest than other three provinces.

The scores of global EI trait $(M=5.170$, Std. Dev.=1.483), well-being $(M=16.219$, Std. Dev.=2.018), self-control $(\mathrm{M}=16.418$, Std. Dev.=2.025), emotionality $(M=22.723$, Std. Dev.=2.151) and sociability $(M=17.645$, Std. Dev.=1.744) of Punjab province are significantly lower than Sindh province but higher than Khyber Pakhtunkhwa and Balochistan.

The scores of global EI trait $(M=4.136$, Std. Dev.=0.972), well-being $(M=13.840$, Std. Dev.=1.850), self-control $(\mathrm{M}=14.272$, Std. Dev.=1.069), emotionality $(\mathrm{M}=18.636$, Std. Dev.=2.600) and sociability $(\mathrm{M}=13.897$, Std. Dev.=1.924) of Khyber Pakhtunkhwa province are significantly lower than Sindh and Punjab provinces but higher than Balochistan province.

The scores of global EI trait $(M=3.476$, Std. Dev.=1.060), well-being $(M=13.619$, Std. Dev.=1.539), self-control $(M=13.127$, Std. Dev.=0.791), emotionality $(M=17.952$, Std. Dev.=3.133) and sociability $(M=12.650$, Std. Dev.=2.208) of Balochistan province are significantly lowest than other three provinces.

\section{Mean Scores Comparison of Four Provinces:}

The scored (17.258) on well-being is higher and Sindh province business managers express their emotion of happiness and pleasure freely and broadly. The massive middle class population is living in the urban areas of Sindh province and it is also a highest individualistic, lowest power distance, second higher feminist and second lowest long term orientation culture of Pakistan founded by Mehmood \& 
Zia et al. [2015]. The individualist cultures observed happiness as a more suitable emotion to show discovered by Matsumoto [1990]. Sindh province managers are extroversion, openness to new experiences and concentrate on personal development, objective in life, and also self-acceptance, it indicate that they are top optimistic culture of Pakistan. Meta-analysis outcomes uncover that persons with independent self-esteem ideas are much more likely than collectivist persons to display positively partial opinions on themselves founded by Heine \& Hamamura [2007]. The managers of Sindh province emphasis on personal achievements and freedom are prioritized over team objectives. Furthermore they also seem to be more self-critical and have a firmly emphasis on negative self-relevant information and facts. It displays that as an individualist culture of Pakistan the province of Sindh concentrate on greatest degrees of subjective well-being. The Diener, Diener \& Diener [1995] founded that individualist cultures have a tendency of greater selfwell-being levels.

Sindh province scores (18.508) on self-control is highest mean score and its reveals that the province of Sindh business managers have powerful skill to deal with stress, potential to manage daily problems without any difficulty and also have great level of emotional regulation capability. Taylor et al. [2007] discovered that individualist cultures confirmed a greater capacity to deal with stress than collectivist cultures. Believe on equal rights, independency and the role of manager as mentor for his/her subordinates increase self-control of Sindh province managers. High individualist cultures, antecedents of emotions, a greater intensity and emotional attributes expression and a greater existence of emotional conformation and less regulation. The individualistic cultures enhance the regulation of emotions exposed by Fernández Itziar; Carrera Pilar; Sánchez Flor; Paez Darío; Candia Luis [2000]. As a highest feminist culture of Pakistan Sindh province managers also have great self-control, display great degrees of emotional activation and extra capabilities to give and obtain emotional assistance.

The Sindh business manager's score on emotionality is (24.133) is higher than other three provinces. The low power distance cultures are more expressive cultures and facial expressions. Matsumoto et al. [2007] revealed that high longterm orientation is related to lowered emotional expressivity. As a lowest long term orientation culture the managers of Sindh province express and display their facial expressions extensively. Duan et al. [2008] proved that individualism predicted intellectual empathy. The managers of Sindh province are really assertive because they concentrate on good results, improvement, competition and generally communicate directly and also ready to command the environment in any circumstance. As a medium long term orientation culture the province Sindh managers do not gives the opinions or point of views strongly and powerfully. It builds the capability to tolerate, observe and recognize the perception of emotions 
of their subordinates. Matsumoto [1990] demonstrated that individualism is directly associated to the facial expression of happiness and sadness.

The business managers of Sindh province scores (17.776) on sociability is higher than three provinces. Earlier researches have confirmed that individualist cultures are more assertive than collective cultures mentioned by Johnson \& Marsella [1978]. The managers of Sindh province have more social awareness and the skills to develop best impression and usually respond well-mannered, cordial and orally smooth during preliminary encounters with others and also express pleasure and sadness. Female managers of Sindh province are more provoked by acts of all those in deeper relationships and male managers are more provoked by acts of strangers. Kelly \& Hutson-Comeaux [1999] disclosed that women were graded as having more frequent characteristic emotions when in personal relationships.

The business managers of Punjab province score on well-being is (16.219) and the culture of Punjab is intermediately individualist, power distance, second higher masculinity and lowest long term orientation culture of Pakistan founded by Mehmood \& Zia et al. [2015]. The managers expect regard, respect and dignity from their subordinates. The province of Punjab managers show the emotions of happiness and enjoy fun in their lives but also focus on their daily responsibilities. Majority of Punjab province population belongs to ruler areas and work as agriculture labor and due to medium economical and financial stability. Their feelings of positive emotions and pleasure are less than Sindh province. Hofstede [1980] revealed that individualists focus on their personal interests and goals more than group. The central point for managers of Punjab is close to individual success but also emphasis on group achievements.

The business managers of Punjab province are on second with score of (16.418) on self-control and managers of Punjab province indicate their emotions which can motivate and maintain or create individual as well as group harmony. As a medium individualist culture they also can moderate their negative emotion generally according to situation. The individualist cultures present themselves positively expressed by Heine, Lehman, Markus, \& Kitayama [1999]. As a member of normative culture the managers are hard-working, show formal and friendly behaviors, and also struggle to achieve quick results.

The business managers of Punjab province are on second with score of (22.723) on emotionality and Punjab province mangers are widely expressive on oral or nonoral responses to their subordinates as a lowest long term orientation culture. The individualist cultures are more effectual to understand and recognize negative and positive emotions discovered by Matsumoto [1989]. The Punjab province managers are medium self-centered and emphasis on truth, economic growth, personal and formal working relationship oriented. They manage their conflicts personally and aim always is to achieve something. 
The business managers of Punjab province are on second with score of (17.645) on sociability and this province is medium masculine culture. Managers of this province have more frequent attribute emotions when in accomplishment scenarios in particular relationships. The Punjab province is medium power distance province and the managers are medium assertive and have medium ability to control their desires. They normally show negative emotions to seniors as they show positive emotions openly but in manner able way. The power distance is related to controlling emotions revealed by Matsumoto et al. [2008]. They always show the emotions of sympathy and understanding to lower status others. As a medium masculine culture the managers of Punjab province show the emotions of strictness but wellmannered and also seeks for self-important. The relationships of Punjab province managers are comparatively estimative and always dependent on dealing to gain something but they also give importance to personal and long term relationships. The individualist cultures give worth to fairness in personal relationships and dominance in working relationship, explained by Triandis [1995].

The Khyber Pakhtunkhwa province business managers are on third position with score (13.840) on well-being. This is highest power distance, masculinity and long term orientation and second collectivist culture of Pakistan founded by Mehmood \& Zia et al. [2015]. Managers of this province display medium to low pleasure and enthusiasm for the concept of feeling positive emotions because of lower income, unstable political, religious and economical conditions, and due to tribal cultural norms and unequal human rights values. The managers from Khyber Pakhtunkhwa give significant to in-group achievements simply because as a second highest collectivist cultures they have a tendency of group-critical and have a stronger emphasis on positive in-group relevant information and facts. Collectivist culture's people concentration on in-group successes and interdependence and have a tendency to have smallest individual-well-being levels founded by Diener, Diener \& Diener [1995]. The managers from Khyber Pakhtunkhwa do not concentrate on their personal desires and dreams, and regulate their behaviors in accordance to their cultural group needs.

The business managers of Khyber Pakhtunk hwa province are on third with score of (14.272) on self-control and as highest long term orientation culture, managers from Khyber Pakhtunkhwa display positive emotions towards seniors and negative to subordinates but pay attention to conformity and obedience towards in-group. As an uncertainty avoidance culture Khyber Pakhtunkhwa province recognized by stress and anxiety and managers express and verbalize their emotions but also have ability to control negative emotion due to highest long term orientation culture.

The business managers of Khyber Pakhtunkhwa province are on third with score of (18.636) on emotionality and as a high power distance culture. Managers demonstrate their authority freely and display adverse emotions when team 
cohesion or group interest is required. Matsumoto [1990] stated that high power distance culture identified expressing adverse emotions toward lower-status other appropriate. The Khyber Pakhtunkhwa is highest masculine culture of Pakistan. Managers from this province are most egoistic and show their aggressiveness, forcefulness and insistent emotions to their subordinates. In masculine cultures, which are recognized by having persons that are aggressive, emotion are not controlled as much as in feminine cultures stated by Hofstede [2001].

The business managers of Khyber Pakhtunkhwa province are on third with score of (13.897) on sociability and managers from this province are low assertive because they generally aim to save face and communicate indirectly. The in-group relationship and collaboration is very essential for them. They expect commitment, loyalty and faithfulness from their subordinates on a regular basis. They regulate their emotions to gain desire outcomes from their subordinates. The high power distance is relevant to managing emotions discovered by Matsumoto [1998]. The province of Khyber Pakhtunkhwa managers are more authoritarian than Punjab and Sindh province. They direct their subordinates clearly and explicitly and also mentioned deadlines highlighted. Managers higher in hierarchy might use a little bit adverse emotions when communicating with their employees. They nurture a greater degree of complying within their group and always surrounded by their in-group members. Managers only display emotions to subordinates which can facilitate group cohesion, harmony or cooperation at greater level. Schimmack [1996] reveals that uncertainty avoidance is relevant to the accuracy and reliability in predicting emotions and as a high uncertainty avoidance province the Khyber Pakhtunkhwa managers have low capability to identify the appropriate emotions of their employees. Khyber Pakhtunkhwa province is high masculine culture and managers of this province are more provoked by acts of strangers in closer relationships, it has founded by Fehr, Baldwin, Collins, Patterson, \& Benditt [1999]. The managers of this province show anger, pride, and contempt emotions. The managers of Khyber Pakhtunkhwa manage their emotional responses to protect the opportunity of future excellent collaborative and long term relationships. As a highest masculine culture of Pakistan, the relationships of this province's managers build their relationship to achieve or complete their tasks or objective. Masculine cultures are more frequent characteristic emotions when in achievement situations discovered by Kelly \& Hutson-Comeaux [1999].

The Balochistan province business managers are at fourth position on well-being score (13.619). Balochistan is highest collectivist, second higher power distance, long term orientation and lowest uncertainty avoidance culture of Pakistan founded by Mehmood \& Zia et al. [2015]. The tribal identity is very powerful in Balochistan culture and they totally communicate indirect in their verbal and nonverbal communication and faithfulness is basic element of this culture. Managers display 
lowest happiness because they are provoked by self-centeredness, uncertain social and economical circumstances but have great ability to identify negative emotions quickly. Matsumoto [1990] founded that collectivist cultures are negatively correlated with determining unhappiness but highly able to recognize the negative emotions. As a second highest long term orientation culture they show hide their negative emotion and display reservedly positive emotions to subordinates because in-group loyalty is very important for managers of Balochistan. They focus on individual adoptability but retaliate and show negative emotions to innovation. The also concentrate on group desires and regulate their emotions according to their tribe or group instead of individual. They strongly focus on negative group-relevant information and facts.

The business managers of Balochistan province are on last with score of (13.127) on self-control and managers from this province preserve their negative emotions and normally hide negative emotions towards subordinates and seek for in-group loyalty and compliance. But managers freely communicate and deliver their emotions of angerness or appreciation where group interest is needed. They tolerate the mistakes of their subordinates and show their support and command and also pay attention to guide and coach them. The collectivist cultures perceptions are wider than individualist discovered by Nisbett \& Masuda [2003].

The business managers of Balochistan province are on last with score of (17.952) on emotionality and as a most collectivist culture of Pakistan; managers focuses on personal relationships and do not shows their actual and real emotions to close in-group people. They show their negative emotions to out-group people but very careful for in-group associates. The collectivist cultures most probably to believe that emotional displays have something to do with their personal connection with an individual showing the emotion, mentioned by Masuda et al. [2008]. The province of Balochistan is highest femininity culture of Pakistan. The managers of this province focus on self-sufficient cooperation and consensus building.

The business managers of Balochistan province are on last with score of (12.650) on sociability and managers from this province are near to near to unassertive. The collective cultures are less assertive than individual cultures stated by Singhal \& Nagao [1993]. They communicate indirect manners and neoplasm is significant value of their culture and they seek long term and unconditional commitment, collaboration and faithfulness. According to Hofstede [2001], femininity is associated to excellent work relationships with others and collaboration at work as a highest femininist culture of Pakistan province of Balochistan managers seek consensus to resolve in-group conflicts and build their relationships and in-group cohesion with their subordinates on the basis of societal solidarity and flexibility and do not show rigid behaviors to them. Collectivist cultures place great emphasis on group cohesion describe by Veenhoven [1999]. 
The global EI trait of Sindh province business managers is highest (6.098) in the comparison of other three provinces and scores on well-being, self-control, emotionality and sociability are also higher than other three provinces. These findings reveals the intention and focus on person goals and objectives, creating in others an appreciation of working activities, and producing and maintaining commitment, confidence, optimism, collaboration and trust in Sindh province managers. It also leads to stimulating flexibility in decision-making and change, and in developing and sustaining a significant identity for an organization.

The province of Punjab managers are on second position on global EI trait with score of (5.170) and scores on well-being, self-control, emotionality and sociability are higher than Khyber Pakhtunkhwa and Balochistan provinces but lower than Sindh. This province manager's concentrates on individual as well as on collective goals and objectives. Strengthen and assertive but less than Khyber Pakhtunkhwa and Balochistan, minimal pessimistic with cooperation and support and democratic decision making are significant trait of Punjab province.

The Khyber Pakhtunkhwa province managers are on third position on global EI trait (4.136) and scores on well-being, self-control, emotionality and sociability are higher than other Balochistan but lower than Sindh and Punjab provinces. The managers of this province emphasize on collective goals. The managers are forceful, dictatorial, authoritarian, pessimistic, and rich influence of power, nonflexible emotions to their subordinates and autocratic decision making are significant traits of Khyber Pakhtunkhwa province.

The Balochistan province managers are on fourth position on global EI trait (3.476) and scores on well-being, self-control, emotionality and sociability are lower than other three provinces. The managers of this province also focus on collective in-group goals. The mangers are powerful, authoritarian, and pessimistic but focus on consensus building, polite and mentor to their in-group associates and collaborative decision making are significant trait of Balochistan province.

These results confirmed the cultural differences in trait emotional intelligence of four provinces of Pakistan. Furthermore, significant differences in global EI trait, well-being, self-control, emotionality and sociability factors have been found in the business managers of four provinces. It verify the role of believes, values, norms, traditions and customs of cultures to shape the trait of emotional intelligence and the four provinces of Pakistan replicate the traits of emotional intelligence accordance to their unique and dissimilar cultures.

\section{Conclusion}

The results of this research provide evidence for the factorial and discriminant validity to TEIQue-SF and significant differences among the trait emotional intelligence of four provinces. Cultural values and norms were related to four 
provinces differences on global EI trait, well-being, self-control, emotionality and sociability, and the relationship among them, and the trait emotional intelligence was correlated with multiple indices of province-level cultural adjustment. The culturalspecific variations provide assistance in shaping and maintain emotions explained by Mayer, Salovey and Caruso [2008]. These findings of trait emotional intelligence show Sindh as highly emotional intelligent province, Punjab as a medium, Khyber Pakhtunkhwa is low to medium and Balochistan as lowest province of Pakistan. This study implies that even with the truth that cultural values and norms performs vital role in the development, display and interpretation of emotions.

\section{Limitations}

The small sample sizes and data gathered only from private sector business organizations of Pakistan are both primary limitations of this research. The participants of this research are business managers and TEQUe-SF was employed as an instrument to measure the trait emotional intelligence in this research. The cultural factors will change within cultures mainly because of demographics, economic classes and other differences within cultures. All participants answered to the trait emotional intelligence measures in English and as a second language may have an impact on the pattern of reactions in this research.

\section{Recommendations}

Future researches can replicate the research with a higher number of participants from not only public, private sector business organizations but also educational institutions. Other comprehensive emotional intelligence measurement tools, models could be used to enhance and confirm the results. The top, middle and lower level business managers are participants in this research but different population groups like genders, employees, teacher and students could be studied separately in futures research. The instrument to measure the trait emotional intelligence should be translated in native languages.

The utilization of emotional intelligence in the organization includes the departments of selection and recruitment, employee development and teams building, organizations necessity train their employees in interpersonal skill building and to perform efficiently on the assignments with other employees in the organization. The culture of Pakistan is vastly influenced by religion and future research should be conduct to measure and compare the trait emotional intelligence among the religious groups of Pakistan. The essential management skills and management styles of the business managers of four provinces should also be compared in future research. The effects and impact of culture on recruitment, training, negotiation, conflict management, performance management and team building should also be focused in future research in the context of these four provinces. 


\section{References}

Adler N.J. (2002), International Dimensions of Organizational Behavior, 4th edition. Cincinnati Ohio: South-Western / Thomson Learning Publishing, pp. 53-55.

Ahmetoglu G., Leutner F., Chamorro T. (2011), EQ-nomics: Understanding the Relationship between Individual Differences in Trait Emotional Intelligence and Entrepreneurship, "Personality and Individual Differences", 51, pp. 1028-1033.

Ang S., Van Dyne L., Koh C., Ng. K.Y., Templer K.J., Tay C., Chandrasekar N.A. (2007), Cultural Intelligence: Its Measurement and Effects on Cultural Judgment and Decision Making, Cultural Adoption and Task Performance, "Management and Organization Review", 3, 335-371. doi:1111/j.1740-8784.2007.00082.x.

Anjum M., Syed Muhammad Zia S., Firoz Shamsi A., Aziz A. (2013), The Impact of Culture on the Perception of Employees and Organizational Productivity in Pharmaceutical Industries in Karachi, "Global Management Journal for Academic \& Corporate Studies" (GMJACS), Vol:03, No: 01. ISSN:2219-6145(2013), http://www.inmic.org/index.php/publicationsgmjacs/1088-the-impact-of-culture-on-the-perception.

Anjum M., Syed Muhammad Zia S., Raza H. (2014), Cultural Dimensions of Pakistan: A Comparison of Sindh, Punjab, Balochistan and Khyber Pakhtunkbwa provinces, "International Journal of Management Sciences", Research Academy of Social Sciences, Vol. 4, No. 6., pp. 261-276.

Arrow H., McGrath J.E., Berdahl J.L. (2000), Small Groups as Complex Systems: Formation, Coordination, Development and Adaptation, Thousand Oaks, CA: Sage.

Bar-On R. (2000), Emotional and Social Intelligence: Insights from the Emotional Quotient Inventory [in:] R. Bar-On, J. D.A. Parker (Eds.), Handbook of Emotional Intelligence, San Francisco: Jossey-Bass, pp. 363-388.

Basabe N., Paez D., Valencia J., Rime B., Pennebaker J., Diener E., Gonzalez J.L. (2000), Socio-cultural Factors Predicting Subjective Experience of Emotion: A Collective Level Analysis, "Psicothema", Vol. 12, pp. 55-69.

Bell J. (2007), The Trouble with Questionnaires [in:] A.R.J. Briggs, M. Coleman (eds.), Research Methods in Educational Leadership and Management ( $2^{\text {nd }}$ Ed.), London: Sage.

Berr J.W., Poortinga Y.H., Segall M.H., Dasen P.R. (2002), Cross Cultural Psychology: Research and Applications (Second, revised Ed.). New York: Cambridge University Press.

Beshart M.A. (2010), The Relationship between Emotional Intelligence and Self-efficacy and Academic Success, "Education Renovation Journal", 2(10), pp. 1-10.

Bostjancic E. (2010), Personality, Job Satisfaction, and Performance of Slovenian Managers--How big is the Role of Emotional Intelligence in this?, "Studia Psychologica", 52(3), pp. 207-218.

Brislin R.W. (1990), Applied Cross-cultural Psychology, Newbury Park, California: Sage Publications.

Bryman A., Bell E. (eds.) (2003-2007), Business Research Method, Oxford: Oxford University Press.

Caruso D.R., Salovey P. (2004), The Emotionally Intelligent Manager: How to Develop and Use the Four Key Emotional Skills of Leadership, San Francisco CA: Jossey-Bass. 
Diener E., Diener M., Diener C. (1995), Factors Predicting Subjective Well-being in Nations, "Journal of Personality and Social Psychology“, 69, pp. 851-864. Doi:10:1037/00223514.69.5.851.

Druskat V., Wolff S. (2001b), Group Emotional Competence and its influence on group effectiveness [in:] C. Cherniss \& D. Goleman (Eds.), The Emotionally Intelligent Workplace, San Francisco: Jossey-Bass, pp. 132-155.

Druskat V.U., Wolff S.B. (2001a), Building the Emotional Intelligence of Groups, "Harvard Business Review", 79(3), pp. 81-90.

Duan C., Wei M., Wang L. (2008), The Role of Individualism-Collectivism in Empathy: An Exploratory Study, "Asian Journal of Counseling”. Vol. 15(1), pp. 57-81.

Fehr B., Baldwin M.W., Collins L., Patterson S., Benditt R. (1999), Anger in Close Relationship: An interpersonal Script Analysis, "Personality and Social Psychology Bulletin", Sage, 25, pp. 299-312.

Fernandez I., Carrera P., Sanchez F., Paez D., Candia I. (2000), Differences between Cultures in Emotional Verbal and Nonverbal Reactions, "Psicothema", núm. Su1, Universidad de Oviedo, Spain, Vol. 12, pp. 83-92.

Goleman D. (1995), “Emotional Intelligence”, New York: Bantam Books.

Goleman D. (1998), Working with Emotional Intelligence, New York: Bantam Books.

Goleman D., McKee A., Boyatzis R.E. (2002), Primal Leadership: Learning to Lead with Emotional Intelligence, Boston: Harvard Business School Press.

Greenspan S.I. (1989), Emotional Intelligence [in:] K. Field, B.J. Choler, G. Wool (Eds.), Learning and Education: Psychoanalytic Perspectives, Madison, CT: International Universities Press, pp. 209-243.

Gross J.J., John O.P. (1998), Mapping the domain of expressivity: Multi-method evidence for a bierarchical model, "Journal of Personality and Social Psychology", Vol. 74(1), pp. 170-191.

Harry C. Triandis, Eunkook M. Suh (2002), Cultural Influences on Personality, "Annual Review of Psychology", Vol. 53, pp. 133-160.

Heine S.J., Hamamura T. (2007), In search of East Asian Self-enhancement, "Personality and Social Psychology Review", Sage, Vol. 11, pp. 4-27.

Heine S.L., Lehman D.R., Markus H.R., Kitayama S. (1999), Is there a Universal need for Positive Self-regard?, "Psychological Review", Vol. 106, pp. 756-794.

Hofstede G. (1980), Culture's Consequences: International Differences in Work-related Values, Beverly Hills, CA: Sage Publications.

Hofstede G. (2001), Culture's Consequences: Comparing Values, Behaviors, Institutions, An Organizations Across Nations, second ed. Sage Publications, Oaks, CA.

Holmer L.L. (1994), Developing Emotional Capacity and Organizational Health [in:] R.H. Kilmann, I. Kilmann \& Associates (Eds.), Managing Ego Energy: The Transformation of Personal Meaning into Organizational Success, San Francisco: Jossey-Bass, pp. 49-72.

Johnson F.A., Marsella A.L. (1978), Differential Attitudes toward Verbal Behavior in Students of Japanese and European Ancestry, 'Genetic Psychological Monographs', 97, pp. 43-76). 
Joseph D.L., Newman D.A. (2010), Emotional Intelligence: An Integrative Meta-analysis and Cascading Model, "Journal of Applied Psychology", 95, pp. 54-78.

Keele S.M., Bell R.C. (2008), The Factorial Validity of Emotional Intelligence: An Unresolved Issue, "Personality and Individual Differences", 44(2), pp. 487-500.

Kelly J.R., Hutson-Comeaux S.L. (1999), Gender-emotion Stereotypes are Context Specific, Sex Roles, Vol. 40, pp. 107-120.

Khalatbari J., Hasani M., Rahmani M.A., Ghorbanshiroudi S., Keikhayfarzaneh M.M. (2011), The Relationship between Emotional Intelligence and Personality Traits with the Thrill Seeking and Self-efficacy in Students of TAU Tonekabon Branch in the academic year 2010-2011, "International Journal of Scientific \& Engineering Research", 2(10), pp. 1-10.

Masuda T., Ellsworth P.C., Mesquita B., Leu J., Tanida S., De Veerdonk E. V. (2008), Placing the Face in Context: Cultural Differences in the Perception of Facial Emotion, "Journal of Personality and Social Psychology, Vol. 94, pp. 365-381.

Matsumoto D. (1989), Cultural Influences on the Perception of Emotion, "Journal of Cross-cultural Psychology", Vol. 20, pp. 92-105.

Matsumoto D. (1990), Cultural Similarities and Differences in Display Rules, "Motivation and Emotion", Vol. 14, pp. 195-214.

Matsumoto D., Seung H.Y., Nakagawa S. (2008), Culture, Emotion Regulation and Adjustment, "Journal of Personality and Social Psychology", Vol. 94, No.6. American Psychological Association, pp. 925-937, DOI: 10.1037/0022-3514.94.6.925.

Matsumoto D., Takeuchi S., Andayani S., Kouznetsova N., Krupp D. (1998), The Contribution of Individualism-collectivism to Cross-national Difference in Display Rules, "Asian Journal of Social Psychology", Vol. 1, pp. 147-165.

Mayer J.D., Salovey P., Caruso D.R. (2000), Emotional Intelligence as Zeitgeist, as Personality, and as a Mental Ability [in:] R. Bar-On, J. Parker (Eds.), The Handbook of Emotional Intelligence, San Francisco, CA: Jossey-Bass, pp. 92-177.

Mayer J.D., Salovey P., Caruso D.R. (2008), Emotional Intelligence: New Ability or Eclectic Traits?, “American Psychologist”, 63 (6), pp. 503-517, DOI: 10.1037/0003-066X.63.6.503.

Miyamoto Y., Ryff C (2011), Cultural Differences in the Dialectical and Non-dialectical Emotional Styles and their Implications for Health, "Cognition and Emotion", 25(1), pp. 22-39.

Nisbett R.E., Masuda T. (2003), Culture and Point of view. Proceedings of the National Academy of Sciences of United States of America, Vol:100, pp. 11163-11175.

Ortony A., Revelle W., Zinbarg R. (2007), Why Emotional Intelligence needs fluid component [in:] G. Mathews, M. Zeidner, R.D. Roberts (Eds.), The Science of Emotional Intelligence, Oxford University Press, pp. 288-304.

Perez J.C., Petrides K.V., Furnham A. (2005), Measuring Trait Emotional Intelligence [in:] R. Schulze, R.D. Roberts (Eds.), Emotional Intelligence: An International bandbook, Cambridge, MA: Hogrefe \& Huber, pp. 181-202.

Petrides K.V. (2009), Technical manual for the trait emotional intelligence questionnaires (TEIQue-SF), London; London Psychometric Laboratory. http://www.psychometriclab.com. 
Petrides K.V., Frederickson N., Furnham A. (2004), The role of Trait Emotional Intelligence in Academic Performance and Deviant Behavior at School, "Personality and Individual Differences", Vol:36, pp. 277-293.

Petrides K.V., Furnham A. (2000), On the Dimensional Structure of Emotional Intelligence, "Personality and Individual Differences", Vol:29, pp. 313-320.

Petrides K.V., Furnham A. (2003), Trait Emotional Intelligence: Behavioral Validation in two studies of emotion recognition and reactivity to mood induction, "European Journal of Personality", $\operatorname{vol}(17)$, pp. 39-57.

Petrides K.V., Pita R., Kokkinaki F. (2007), The Location of Trait Emotional Intelligence in Personality Factor Space, "British Journal of Psychology", Vol:98, pp. 273-289.

Petrides K.V., Vernon P.A., Schermer J.A., Lighthart L., Boomsma D.I., Veselka L. (2010), Relationships between trait emotional intelligence and the Big Five in the Netherlands, "Personality and Individual Differences", Vol: 48, pp. 906-910.

Robbins S.P., Judge T.A. (2014), Essentials of Organizational Behavior, Pearson Education Limited, England.

Robinson M.D., Clore G.L. (2002), Belief and feeling: Evidence for an Accessibility Model of Emotional Self-report, 'Psychology Press', Vol:9, pp. 87-111.

Rossen E., Kranzler J.H., Algina J. (2008), Confirmatory Factor Analysis of the Mayer Salovey-Caruso Emotional Intelligence Test V 2.0 (MSCEIT), "Personality and Individual Differences", Vol:44, pp.1258-1269.

Salovey P., Grewal D. (2005), The Science of Emotional Intelligence, "American Psychological Society", Vol (14) No. 6, pp. 281-285.

Salovey P., Mayer J.D. (1990), Emotional Intelligence, "Imagination, Cognition and Personality", vol:9, pp. 185-211.

Schimmack U. (1996), Cultural Influences on the Recognition of Emotion by Facial Expression: Individualistic or Caucasian Cultures?, "J. Cross-culture Psychology", Vol:27, pp. 37-50.

Singh P., Manser P., Mestry R. (2007). Importance of Emotional Intelligence in Conceptualizing Collegial Leadership in Education, "South African Journal of Education", vol. 27(3), pp. 541-563.

Singhal A., Nagao M. (1993), Assertiveness as Communication Competence: A Comparison of the Communication Styles of American and Japanese Students, "Asian Journal of Communication", 3 (1), pp. 1-18.

Taylor S.E., Welch W.T., Kim H.S., Sherman D.K. (2007), Cultural differences in the impact of social support on psychological and biological stress responses, "Psychological Science", 18, 831-837.

Triandis H.C. (1995), Individualism \& Collectivism, Boulder, CO: Westview Press.

Van Maanen J., Kunda G. (1989), "Real feelings": Emotional Expression and Organizational Culture, [in:] B. Staw (Ed.), Research in Organizational Behavior, Greenwich, CT: JAI Press. Vol:11, pp. 43-103.

Veenhoven R. (1999), Quality of life Individualistic Society: A Comparison of 43 Nations in the early 1990s, "Social Indicators Research", vol. 48, pp. 157-186. 
Vernon P.A., Vilani V.C., Schermer J.A., Petrides K.V. (2008), Phenotypic and Genetic Associations between the Big Five and Trait Emotional Intelligence, "Twin Research and Human Genetics", Volume 11 Number 5, pp. 524-530.

Weick K. (1995), Sensemaking in Organizations, Thousand Oaks: Sage Publications. 